\title{
Tensile mechanical response of polyethylene - clay nanocomposites
}

\author{
A. Pegoretti* , A. Dorigato, A. Penati \\ Department of Materials Engineering and Industrial Technologies, and INSTM Research Unit, University of Trento, via \\ Mesiano 7, 38050 Trento, Italy
}

Received 22 December 2006; accepted in revised form 14 February 2007

\begin{abstract}
In this work we report on the microstructural and the mechanical characteristics of high density polyethylene (HDPE)-clay nanocomposites, with particular attention to the creep behaviour. The samples were prepared through melt compounding, using two high-density polyethylenes with different melt flow rate (MFR), two different organo-modified clays, and changing the relative amount of a polyethylene grafted with maleic anhydride (PEgMA) compatibilizer. The intercalation process is more effective as the matrix melt viscosity decreases (higher MFR), while the clay interlamellar spacing increases as the compatibilizer amount increases. The relative stiffness of the nanocomposites increases with the addition of clay, with a limited enhancement of the relative yield stress. The better intercalation obtained by the addition of the compatibilizer is not accompanied by a concurrent improvement of the tensile mechanical properties. The creep resistance is enhanced by the introduction of clay, with an appreciable dependence on both the polyethylene and the clay type.
\end{abstract}

Keywords: polymer composites, nanomaterials, polyethylene, clay, creep

\section{Introduction}

The effective dispersion of nanostructured layered silicates with high aspect ratios may improve the mechanical, thermal and barrier properties of polymers, even at very low concentration [1-3]. Highdensity polyethylene (HDPE) is a commodity polymer broadly used for many industrial products. One of the most demanding applications of HDPE is the production of pipes and fittings for the transportation of water or gas under pressure. In this case, the creep behaviour is a very important property to be considered for the material selection. The preparation of HDPE-clay nanocomposites remains a scientific challenge. In fact the studies on HDPEclay nanocomposites have been relatively few if compared to the huge literature existing on clay nanocomposites obtained with more polar polymers [4]. Effectively, polyolefins are difficult to intercalate in the interlayer space of hydrophilic swelling clays without chemical modification of one of the two pristine components. In order to solve the problem of the lack of interfacial adhesion between apolar polyethylene (PE) and polar layered silicates, the addition of PE grafted with maleic anhydride to the PE matrix has been proven to favour the intercalation/exfoliation process, with important improvements of the material stiffness, maintaining the ultimate stress and strain at an acceptable level [5-7].

In order to obtain a good chemical affinity between polyethylene and clay, the use of organoclay with high hydrophobicity is recommended $[8,9]$, and some researchers tried to use different organo-modifiers for clay functionalization [10-12]. Even if a number of papers have been published on the mechanical properties of melt-compounded PEclay nanocomposites [4, 6, 13-27], only Ranade et al. reported on their response to tensile creep [23].

*Corresponding author, e-mail: alessandro.pegoretti@ing.unitn.it (C) BME-PT and GTE 
In particular, these authors found a substantial reduction of the creep compliance of HDPE blown films through the introduction of Cloisite ${ }^{\circledR} 15 \mathrm{~A}$ clay and maleated polyethylene, and they successfully applied the Burger model to model the experimental data.

In this paper we used two different tube-grade polyethylenes and two different organoclays to produce PE-clay nanocomposites with and without a compatibilizer. The aim is to investigate the influence of the melt viscosity of the matrix, of the organoclay and compatibilizer concentrations on the microstructure and the mechanical behaviour of the resulting nanocomposites, with particular attention to the creep resistance.

\section{Experimental}

\subsection{Materials}

Two high density polyethylenes, having markedly different melt viscosities, were used:

- Lupolen $5031 \mathrm{~L}$ Q 449, density $0.952 \mathrm{~g} / \mathrm{cm}^{3}$, melting temperature $131^{\circ} \mathrm{C}$, MFR $6.5 \mathrm{~g} / 10 \mathrm{~min}$ $\left(190^{\circ} \mathrm{C}, 2.16 \mathrm{~kg}\right)$;

- Eltex A 4009 MFN 1325, density $0.960 \mathrm{~g} / \mathrm{cm}^{3}$, melting temperature $134^{\circ} \mathrm{C}$, MFR $0.9 \mathrm{~g} / 10 \mathrm{~min}$ $\left(190^{\circ} \mathrm{C}, 2.16 \mathrm{~kg}\right)$.

Both matrices were received in the form of fine powders.

Commercial organoclays Cloisite ${ }^{\circledR}$ 20A and Cloisite $^{\circledR}$ 15A were supplied by Southern Clay Products Inc. These clays contain the same organomodifier, namely dimethyl dihydrogenated tallow ammonium (2M2HT), but in different concentrations, i.e. $95 \mathrm{meq} / 100 \mathrm{~g}$ for Cloisite ${ }^{\circledR} 20 \mathrm{~A}$ and $125 \mathrm{meq} / 100 \mathrm{~g}$ for Cloisite ${ }^{\circledR} 15 \mathrm{~A}$. These two clays are among the most hydrophobic fillers of the Cloisite ${ }^{\circledR}$ series, due to the presence of long hydrocarbon chains in the organic modifier. In fact, hydrogenated tallow consists of about $65 \% \mathrm{C} 18$, $30 \% \mathrm{C} 16$, and 5\% C14 fractions. Maleic anhydride grafted polyethylene Fusabond E MB 100D (DuPont) was used as compatibilizer. This compatibilizer has a density of $0.960 \mathrm{~g} / \mathrm{cm}^{3}$, a MFR of $2 \mathrm{~g} / 10 \mathrm{~min}\left(190^{\circ} \mathrm{C}, 2.16 \mathrm{~kg}\right)$, a melting temperature of $134^{\circ} \mathrm{C}$, a maleic anhydride content of $0.9 \mathrm{wt} \%$.

Since both compatibilizer and clay amounts were changed, the samples will be named in the order of HDPE/PEgMA/clay weight ratios hereafter.

\subsection{Sample preparation}

The preparation process was the same for all the composites. At first, the required amount of clay was mixed with HDPE powder and the compatibilizer with a mechanical stirrer (Dispermat F1), for 5 minutes at $500 \mathrm{rpm}$. The mixture was then melt compounded in a Thermo Haake Reomix 600p internal mixer working at $90 \mathrm{rpm}$ at a temperature of $180^{\circ} \mathrm{C}$ for 17 minutes. The temperature was maintained relatively low in order to limit the organoclay degradation [28]. Square sheets (160 mm wide and $1.5 \mathrm{~mm}$ thick) were finally obtained by compression moulding in a Carver Laboratory press for 15 minutes at $180^{\circ} \mathrm{C}$ at a consolidation pressure of about $200 \mathrm{kPa}$.

\subsection{Experimental methodologies}

$\mathrm{X}$-ray diffraction (XRD) analyses were performed by a Philips Xpert HRD diffractometer, using $\mathrm{Cu}$ $\mathrm{K} \alpha(\lambda=0.15406 \mathrm{~nm})$ radiation, generated at a voltage of $40 \mathrm{kV}$ and current of $30 \mathrm{~mA}$. The diffraction angle $2 \theta$ was scanned from $1.75^{\circ}$ to $10^{\circ}$ at a step increment $\Delta \theta$ of $0.1 \%$ s. By using Bragg' law, the XRD patters were used to calculate d-spacings of the clay layers. A relative intercalation (RI) of the clay in the polymeric matrix has been computed as a percentage increase of the $\mathrm{d}$-spacing according to the following equation:

$\mathrm{RI}=\left(\frac{d-d_{0}}{\mathrm{~d}_{0}}\right) 100$

where $d_{0}$ and $d$ are the d-spacings of the pristine clay and the clay in the nanocomposites, respectively.

Tensile tests under constant rate and creep conditions were performed by an Instron 4502 universal testing machine on specimens punch-cut from the compression moulded plaques. Constant rate experiments were conducted on ISO 527 1BA dumbbell specimens. The tensile modulus was evaluated at a cross-head speed of $0.25 \mathrm{~mm} / \mathrm{min}$ by using an electrical clip gage extensometer with a gage length of $12.5 \mathrm{~mm}$. According to ISO 527 standard, the modulus was calculated as a secant modulus between $0.05 \%$ and $0.25 \%$ strain. The same specimens were used for the evaluation of the yield and fracture tensile parameters at a cross-head speed of $50 \mathrm{~mm} / \mathrm{min}$. The creep tests were conducted on rectangular strips $60 \mathrm{~mm}$ long and $5 \mathrm{~mm}$ 


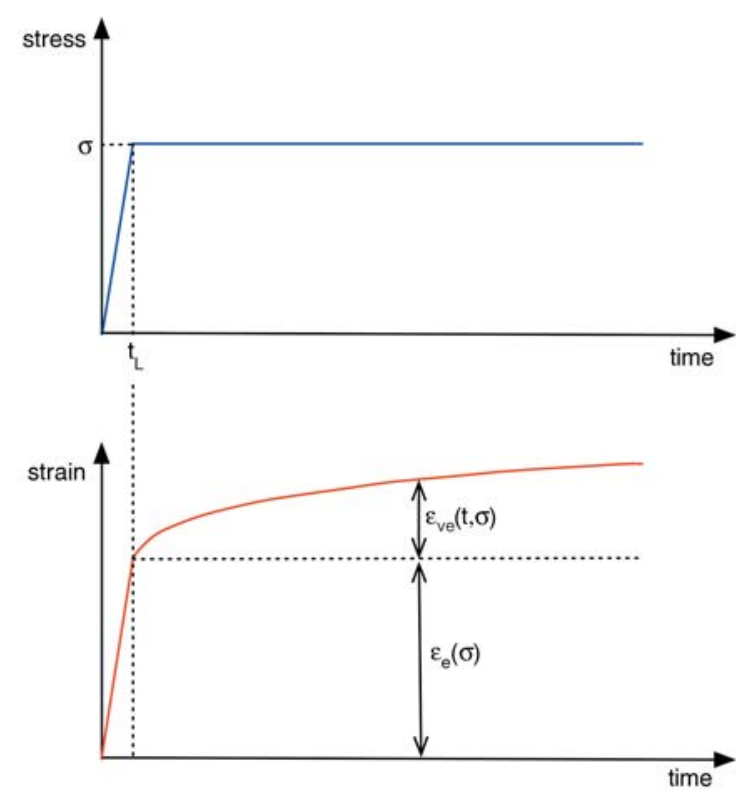

Figure 1. Schematic of the creep experiments and strain components

wide, in a thermostatic chamber at $30^{\circ} \mathrm{C}$, at a constant nominal stress $\left(\sigma_{0}\right)$ of $10 \mathrm{MPa}$. A schematic of the creep experiments is detailed in Figure 1. The loading ramp was performed at a cross-head speed of $25 \mathrm{~mm} / \mathrm{min}$ that resulted in a loading time $\left(t_{L}\right)$ always lower than $2 \mathrm{~s}$.

\section{Results and discussion}

\subsection{X-ray diffraction measurements}

From the data reported in Table 1 it is evident that for both types of clays, Lupolen/clay intercalation is markedly promoted by PEgMA compatibilizer. In some cases, for non-compatibilized composites, negative RI values are reported, indicating a slight reduction of the clay interlayer distance. This phe- nomenon has been already reported by Shah et al. [28] and attributed to a processing-induced degradation of the quaternary ammonium surfactant of the organoclay. The data reported in Table 1 also reveal that, for a given compatibilizer amount, Cloisite ${ }^{\circledR} 20 \mathrm{~A}$ can be intercalated to a much higher extent than Cloisite ${ }^{\circledR} 15 \mathrm{~A}$, thus indicating a better intercation of Cloisite ${ }^{\circledR} 20 \mathrm{~A}$ with both Lupolen and Eltex HDPE matrices. As described in the experimental part, the two organoclays contain the same type of organomodifier but in different concentrations. As a consequence, Cloisite ${ }^{\circledR} 15 \mathrm{~A}$ is slightly less hydrophobic than Cloisite ${ }^{\circledR} 20 \mathrm{~A}$, as recently assessed by measuring the vibration induced equilibrium contact angles of water droplets on clay disks[29]. The slightly lower hydrophobicity of Cloisite ${ }^{\circledR} 20 \mathrm{~A}$ may account for the better intercalation observed when the PEgMA compatibilizer is introduced in the system.

It is worthwhile to note that the intercalation process is far more effective for Lupolen than for Eltex based HDPE nanocomposites. This result can be explained by considering that the two polymeric matrices have markedly different MFR values, and the lower viscosity of the Lupolen is surely responsible of the better polymer-clay intercalation. This is in contrast with literature data on polyamide 6 where a better delamination was obtained by increasing the molecular weight of the polymer [30]: this result was attributed to the mechanical assistance to delamination of the clay by the larger shear stress in the extrusion process due to the larger melt viscosity of the polymer with larger molecular weight. On the other hand, our findings are in agreements with the experimental works on polyolefin-clay nanocomposites $[31,32]$. In partic-

Table 1. XRD results of HDPE/PEgMA/clay nanocomposites

\begin{tabular}{|c|c|c|c|c|c|c|}
\hline Sample composition & \multicolumn{3}{|c|}{ Lupolen } & \multicolumn{3}{|c|}{ Eltex } \\
\hline HDPE/PEgMA/clay & $\begin{array}{c}001 \text { peak } 2 \theta \\
\text { [deg] }\end{array}$ & $\begin{array}{c}\mathbf{d} \\
{[\mathrm{nm}]}\end{array}$ & $\begin{array}{c}\text { RI } \\
{[\%]}\end{array}$ & $\begin{array}{c}001 \text { peak } 2 \theta \\
\text { [deg] }\end{array}$ & $\begin{array}{c}\mathbf{d} \\
{[\mathrm{nm}]}\end{array}$ & $\begin{array}{l}\text { RI } \\
{[\%]}\end{array}$ \\
\hline \multicolumn{7}{|l|}{ Cloisite $^{\circledR}$ 15A } \\
\hline $0 / 0 / 100$ & 2.85 & 3.098 & - & 2.85 & 3.098 & - \\
\hline $98 / 0 / 2$ & 2.76 & 3.198 & 3.26 & - & - & - \\
\hline $95 / 0 / 5$ & 2.90 & 3.044 & -1.72 & - & - & - \\
\hline $88 / 10 / 2$ & 2.65 & 3.331 & 7.55 & 2.95 & 2.993 & -3.39 \\
\hline $85 / 10 / 5$ & 2.75 & 3.210 & 3.64 & 2.75 & 3.210 & 3.64 \\
\hline \multicolumn{7}{|l|}{ Cloisite $^{\circledR}$ 20A } \\
\hline $0 / 0 / 100$ & 3.30 & 2.675 & - & 3.30 & 2.675 & - \\
\hline $98 / 0 / 2$ & 3.15 & 2.803 & 4.76 & - & - & - \\
\hline $95 / 0 / 5$ & 3.40 & 2.597 & -2.94 & - & - & - \\
\hline $88 / 10 / 2$ & 2.65 & 3.331 & 24.52 & 3.05 & 2.894 & 8.19 \\
\hline $85 / 10 / 5$ & 2.65 & 3.331 & 24.52 & 3.15 & 2.803 & 4.76 \\
\hline
\end{tabular}


ular, Giannelli et al. [31] studied the effect of the polypropylene based resin on the properties of organoclay-PP nanocomposites prepared by melt compounding using a twin screw extruder, and reported that the delamination of organoclays is favoured at high MFR for both homopolymers and heterophasic copolymers. In this case it seems that the organophilic environment, created in the layers interspace by combination of the organic cation and maleic anhydride grafted polypropylene, drives the delamination process through thermal diffusion control, making mechanical contribution negligible. In the present case a similar explanation could be invoked to explain our experimental results.

Following these preliminary results, the effect of the compatibilizer amount on the Cloisite ${ }^{\circledR} 20 \mathrm{~A}$ intercalation level in Lupolen HDPE matrix has been investigated, and the results are summarized in Figure 2. It is clearly evident that the intercalation level almost linearly increases as the weight

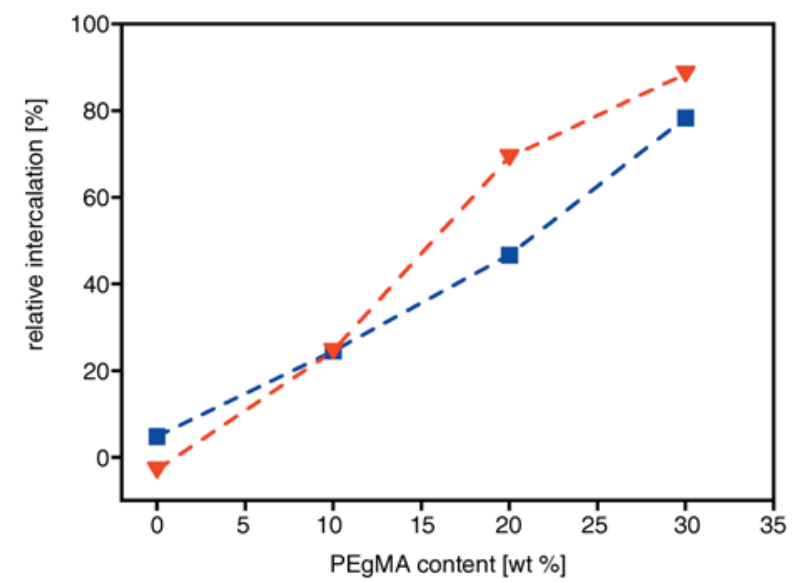

Figure 2. Effect of the PEgMA content on the relative intercalation of ( $\mathbf{\square}) 2 \mathrm{wt} \%$ and $(\nabla) 5 \mathrm{wt} \%$ of Cloisite 20A in the Lupolen HDPE matrix fraction of compatibilizer increases. Moreover, for the compatibilized samples the intercalation degree increases as the clay loading increases. In the existing literature, contradictory results are reported on this point. In fact, consistently with our observations, some authors reported an increase of the intercalation level with the clay loading $[2,11,27]$, while other authors observed an opposite trend [33, 34].

\subsection{Constant rate tensile tests}

As for most thermoplastics, the deformation was uniform along the gauge length up to the yield point (conventionally evaluated in correspondence of the zero-slope point on the engineering stress-strain curve). After the yield point, a neck in formed in the specimens and the permanent deformation is localized in this region that gradually extends to the whole gauge length. Table 2 summarizes the tensile modulus $(E)$, yield stress $\left(\sigma_{y}\right)$ and strain at break $\left(\varepsilon_{r}\right)$ values of Lupolen and Eltex HDPE matrices both neat and filled with 2 and $5 \mathrm{wt} \%$ of Cloisite ${ }^{\circledR}$ $15 \mathrm{~A}$ and $20 \mathrm{~A}$ clays, with or without a $10 \mathrm{wt} \%$ of PEgMA compatibilizer.

For both HDPE matrices, the introduction of the compatibilizer at this percentage causes a slight decrease of the tensile modulus, remaining the yield stress and strain at break values practically unchanged. The effect of clay addition is markedly dependent on the polymer-clay intercalation level. In fact, for non-compatibilized samples (low intercalation level) the addition of Cloisite ${ }^{\circledR} 15 \mathrm{~A}$ and $20 \mathrm{~A}$ clays at 2 and $5 \mathrm{wt} \%$ does not cause an appreciable tensile modulus variation, that is instead observed for nanocomposites with PEgMA com-

Table 2. Tensile mechanical properties of HDPE/PEgMA/clay nanocomposites

\begin{tabular}{|c|c|c|c|c|c|c|}
\hline Sample composition & \multicolumn{3}{|c|}{ Lupolen } & \multicolumn{3}{|c|}{ Eltex } \\
\hline HDPE/PEgMA/clay & $\begin{array}{c}\mathbf{E} \\
{[\mathbf{M P a}]}\end{array}$ & $\begin{array}{c}\sigma_{\mathbf{y}} \\
{[\mathrm{MPa}]}\end{array}$ & $\begin{array}{c}\varepsilon_{\mathrm{r}} \\
{[\%]}\end{array}$ & $\begin{array}{c}\mathbf{E} \\
{[\mathrm{MPa}]}\end{array}$ & $\begin{array}{c}\sigma_{\mathbf{y}} \\
{[\mathrm{MPa}]}\end{array}$ & $\begin{array}{c}\varepsilon_{\mathrm{r}} \\
{[\%]}\end{array}$ \\
\hline $100 / 0 / 0$ & $932 \pm 41$ & $27.7 \pm 0.1$ & $1173 \pm 50$ & $1252 \pm 32$ & $30.5 \pm 0.2$ & $1650 \pm 302$ \\
\hline $90 / 10 / 0$ & $877 \pm 36$ & $27.2 \pm 0.3$ & $922 \pm 282$ & $1168 \pm 75$ & $30.6 \pm 0.2$ & $1697 \pm 566$ \\
\hline \multicolumn{7}{|l|}{ Cloisite $^{\circledR}$ 15A } \\
\hline $98 / 0 / 2$ & $934 \pm 18$ & $27.7 \pm 0.5$ & $166 \pm 23$ & - & - & - \\
\hline $95 / 0 / 5$ & $928 \pm 21$ & $26.0 \pm 0.4$ & $36 \pm 25$ & - & - & - \\
\hline $88 / 10 / 2$ & $1156 \pm 45$ & $27.8 \pm 0.4$ & $225 \pm 97$ & $1283 \pm 114$ & $29.7 \pm 0.1$ & $1406 \pm 809$ \\
\hline $85 / 10 / 5$ & $1112 \pm 64$ & - & $14 \pm 8$ & $1379 \pm 85$ & $28.7 \pm 0.1$ & $21 \pm 7$ \\
\hline \multicolumn{7}{|l|}{ Cloisite $^{\circledR}$ 20A } \\
\hline $98 / 0 / 2$ & $917 \pm 62$ & $28.2 \pm 0.2$ & $172 \pm 18$ & - & - & - \\
\hline $95 / 0 / 5$ & $975 \pm 87$ & $26.7 \pm 0.3$ & $14 \pm 3$ & - & - & - \\
\hline $88 / 10 / 2$ & $1147 \pm 40$ & $28.1 \pm 0.2$ & $51 \pm 45$ & $1400 \pm 65$ & $30.3 \pm 0.2$ & $692 \pm 516$ \\
\hline $85 / 10 / 5$ & $1184 \pm 37$ & - & $10 \pm 2$ & $1341 \pm 75$ & $29.6 \pm 0.7$ & $18 \pm 7$ \\
\hline
\end{tabular}


patibilizer. The elastic modulus improvements are higher for the Lupolen than for Eltex based nanocomposites. The $5 \mathrm{wt} \%$ Cloisite $^{\circledR}$ 20A filled Lupolen sample, with $10 \mathrm{wt} \%$ compatibilizer, shows an enhancement of the $35 \%$ of the elastic modulus, compared to the unfilled compatilized matrix, while the improvement for the Eltex sample, filled with the same amount of the same clay, is $15 \%$. Moreover, the stiffness improvement is more effective for Cloisite ${ }^{\circledR} 20 \mathrm{~A}$ filled nanocomposites than for Cloisite ${ }^{\circledR}$ 15A filled nanocomposite, confirming the microstructural observations of the XRD tests.

For as the yield stress is concerned, the $2 \mathrm{wt} \%$ filled Lupolen nanocomposites show a little but significant enhancement of the yield point, when the compatibilizer is used. When an higher clay amount of $5 \mathrm{wt} \%$ is introduced, sample breakage occurs before the yield point is reached. For the Eltex based nanocomposites, a decrease of $\sigma_{y}$ is evident, which accounts for a weaker polymer-clay interaction. The yield stress improvements are higher for the Cloisite ${ }^{\circledR} 20$ A filled nanocomposite. It is worthwhile to note, that a $\sigma_{y}$ enhancement, even if small, is an indicator of a good filler matrix interaction [17, 22-24]. At the same time, the introduction of clay in these HDPE matrices has detrimental effects on the elongation at break of the resulting nanocomposites, the worst case being that of $5 \mathrm{wt} \%$ clay filled Lupolen nanocomposites that break before yielding.

In order to assess an optimal amount of PEgMA compatibilizer, its effect on the tensile modulus and yield strength of Lupolen based nanocomposites filled with 2 and 5 wt $\%$ of Cloisite ${ }^{\circledR} 20 \mathrm{~A}$ has been

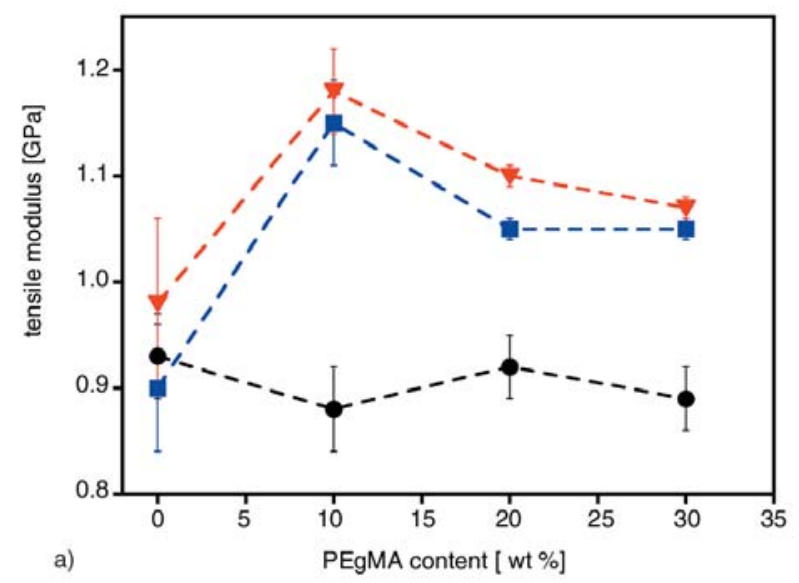

assessed. The obtained results are reported in Figure 3.

For any given PEgMA concentration the tensile modulus increases proportionally to the clay content. It is worthwhile to note that, for elevated amounts of compatibilizer $(20-30 \mathrm{wt} \%)$, the expected modulus improvement related to the better polymer-clay intercalation is not occurring, and that an optimal compatibilizer concentration can be detected at $10 \mathrm{wt} \%$. A similar result has been observed by Hotta and Paul [17] for organoclay filled nanocomposites based on linear low density polyethylene (LLDPE). In fact, when the amount of compatibilizer consisting of maleic anhydride grafted linear low density polyethylene (LLDPE-gMA) is varied, these authors observed a slight maximum in both modulus and yield strength in the blends occurring at about $10 \mathrm{wt} \%$ of LLDPE-gMA.

Concurrently, the presence of high compatibilizer amounts causes a significant reduction of the tensile yield strength, both for the unfilled matrix and for the nanocomposites filled with $2 \mathrm{wt} \%$ and $5 \mathrm{wt} \%$ of Cloisite ${ }^{\circledR}$ 20A. A quite unexpected result is represented by the very low yield strength value observed for the uncompatibilized composites filled with $5 \mathrm{wt} \%$ clay, which is suggesting a possible lubricating effect of the clay platelets at this loading level.

\subsection{Tensile creep tests}

The strain in isothermal tensile creep, $\varepsilon(t, \sigma)$, depending on time $t$ and stress $\sigma$, is usually viewed as consisting of three components: [35-37] (i) elas-

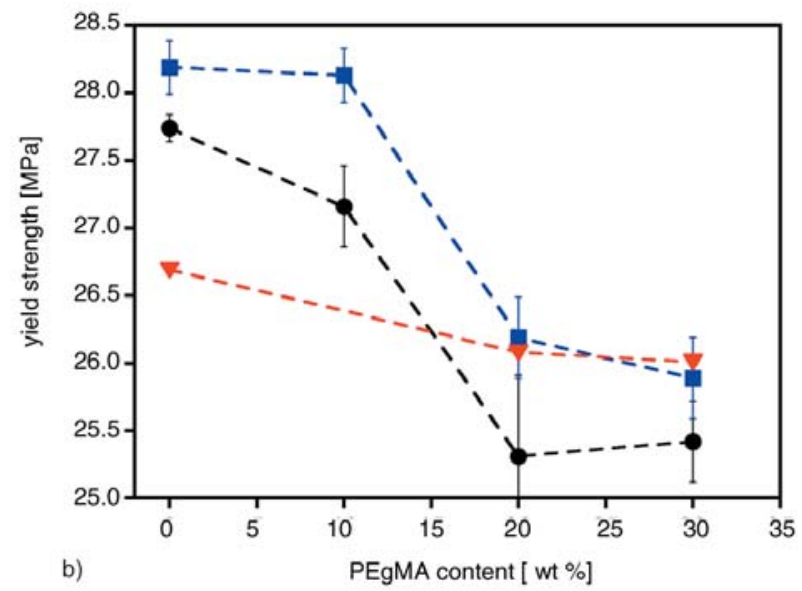

Figure 3. Effect of the PEgMA content on the a) tensile modulus and b) yield strength of the HDPE Lupolen matrix unfilled $(\bullet)$, and filled with $2 \mathrm{wt} \%(\boldsymbol{\nabla})$ and $5 \mathrm{wt} \%(\boldsymbol{\nabla})$ of Cloisite $^{\circledR} 20 \mathrm{~A}$ 
tic (instantaneous, reversible) $\varepsilon_{e}(\sigma)$; (ii) viscoelastic (time-dependent, reversible) $\varepsilon_{v e}(t, \sigma)$; (iii) plastic (irreversible) $\varepsilon_{p}(t, \sigma)$ :

$\varepsilon(t, \sigma)=\varepsilon_{e}(\sigma)+\varepsilon_{v e}(t, \sigma)+\varepsilon_{p}(t, \sigma)$

Linear stress-strain behavior implies that the magnitudes of the three components are linearly proportional to the magnitude of the applied stress, so that a creep compliance $D(t)=\varepsilon(t) / \sigma$ can be defined as a function of time only. If no plastic deformation is produced in the course of creeping, the tensile compliance $D(t, \sigma)=\varepsilon(t, \sigma) / \sigma$ for the isothermal creep reads

$D(t)=D_{e}+D_{v e}(t)$

In the current study, Equation (3) has been adopted to analyse the experimental data. In fact, all the experiments have been performed under the same applied stress in order to avoid non-linearity effects. Moreover, the specimens recovered their initial length after unloading, thus excluding the presence of plastic deformations.

Representative curves of total creep compliance of Lupolen and Eltex based samples are reported in Figure $4 \mathrm{a}$ and $4 \mathrm{~b}$, respectively. Interestingly, at any

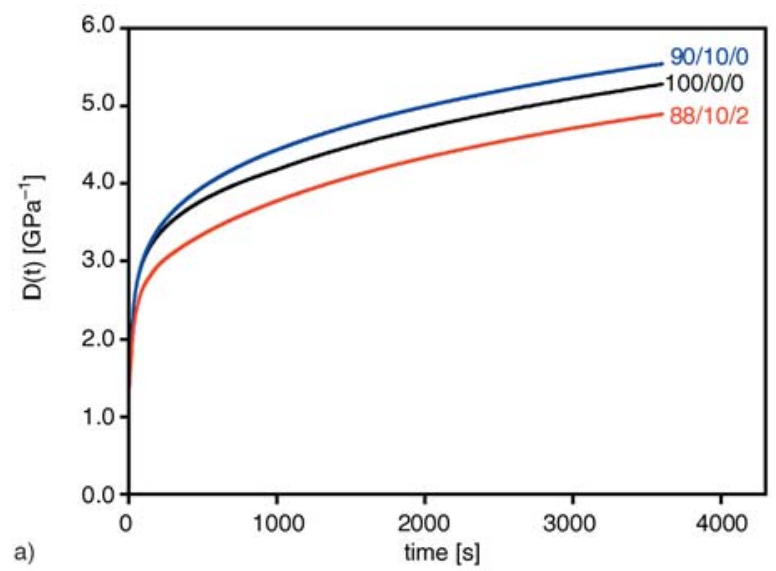

time within the experimental window, the presence of $10 \mathrm{wt} \%$ of PEgMA compatibilizer leads to an increase of the creep compliance, while the introduction of $-2 \mathrm{wt} \%$ of Cloisite ${ }^{\circledR} 20 \mathrm{~A}$ clay causes an appreciable reduction of the creep compliance. It is also worthwhile to note that the creep resistance of Lupolen and Eltex based nanocomposites is improved by the same level regardless the different intercalation levels reached for the two matrices. This experimental evidence is in agreement with the results recently reported by Siengchin and Karger-Kocsis [38] on the creep behaviour of polystyrene/fluorohectorite micro- and nanocomposites. In fact, these authors observed that the creep compliance curves of micro and nano-composites lay parallel to one another, at least until a given threshold, thus indicating that the creep response in this stable creep range is matrix dominated. As a consequence, the major effect of the reinforcement is the reduction of the initial compliance.

Table 3 summarizes the isochronous creep compliance components of Cloisite ${ }^{\circledR}$ 20A filled nanocomposites with or without $10 \mathrm{wt} \%$ of PEgMA compatibilizer. The data obtained for Lupolen based samples indicate that an improvement of the creep resistance can be reached only if the compat-

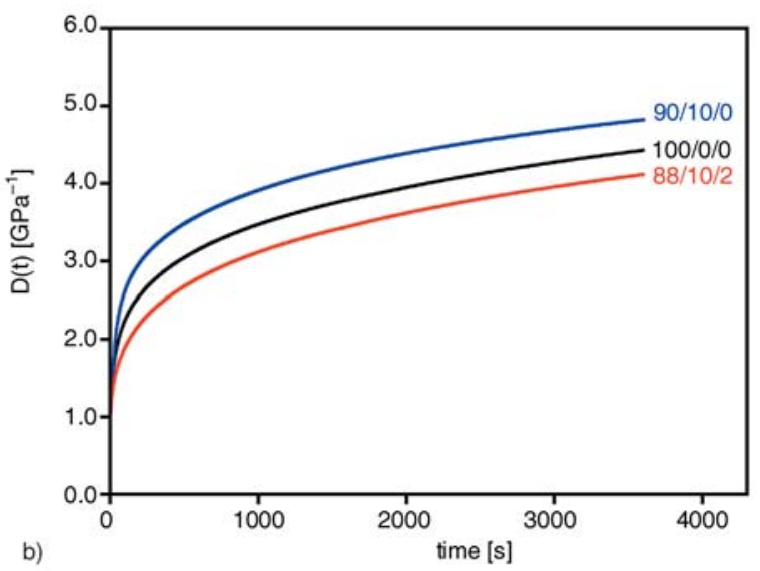

Figure 4. Typical creep curves of some HDPE/PEgMA/clay nanocomposites based on a) Lupolen and b) Eltex HDPE matrices and filled with Cloisite $^{\circledR} 20$ A clay

Table 3. Isochronous creep compliance $(D)$ and its elastic $\left(D_{e}\right)$ and viscoelastic $\left(D_{v e}\right)$ components at a time of $2000 \mathrm{~s}$ for HDPE nanocomposites filled with Cloisite ${ }^{\circledR} 20 \mathrm{~A}$

\begin{tabular}{|c|c|c|c|c|c|c|}
\hline Sample composition & \multicolumn{3}{|c|}{ Lupolen } & \multicolumn{3}{|c|}{ Eltex } \\
\hline HDPE/PEgMA/clay & $\mathrm{D}\left[\mathrm{GPa}^{-1}\right]$ & $\mathrm{D}_{\mathrm{e}}\left[\mathrm{GPa}^{-1}\right]$ & $\mathrm{D}_{\mathrm{ve}}\left[\mathrm{GPa}^{-1}\right]$ & $\mathrm{D}\left[\mathrm{GPa}^{-1}\right]$ & $\mathrm{D}_{\mathrm{e}}\left[\mathrm{GPa}^{-1}\right]$ & $\mathrm{D}_{\mathrm{ve}}\left[\mathrm{GPa}^{-1}\right]$ \\
\hline $100 / 0 / 0$ & 4.722 & 1.462 & 3.260 & 3.948 & 0.942 & 3.006 \\
\hline $90 / 10 / 0$ & 4.995 & 1.415 & 3.580 & 4.391 & 1.100 & 3.291 \\
\hline $98 / 0 / 2$ & 5.002 & 1.592 & 3.410 & - & - & - \\
\hline $95 / 0 / 5$ & 4.901 & 1.433 & 3.467 & - & - & - \\
\hline $88 / 10 / 2$ & 4.331 & 1.279 & 3.052 & 3.622 & 0.878 & 2.744 \\
\hline $85 / 10 / 5$ & 4.752 & 1.187 & 3.565 & 3.792 & 0.895 & 2.897 \\
\hline
\end{tabular}



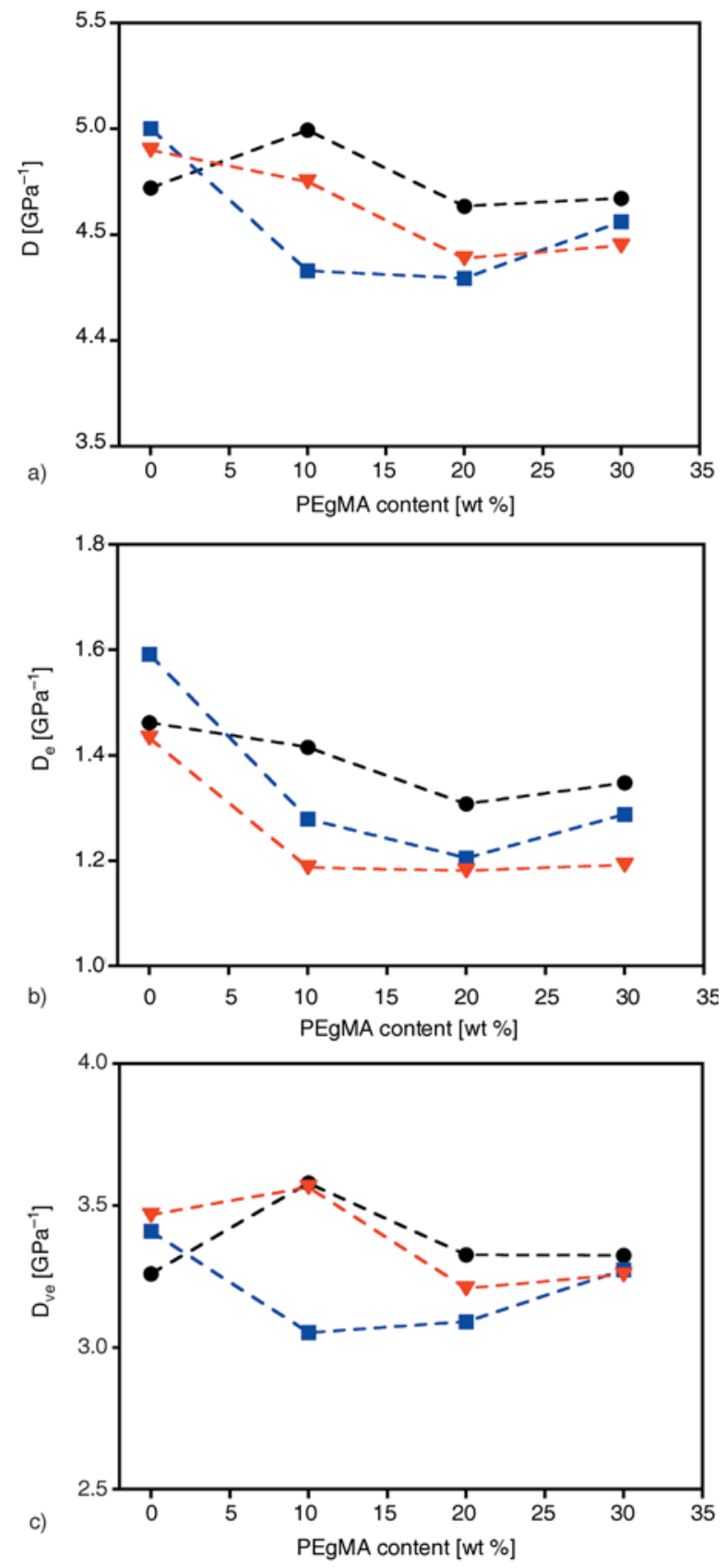

Figure 5. Isochronous creep compliance a) and its elastic b), and viscoelastic c) components at a time of $2000 \mathrm{~s}$ for HDPE Lupolen matrix unfilled $(\bullet)$, and filled with $2 \mathrm{wt} \%(\boldsymbol{\square})$ and $5 \mathrm{wt} \%(\boldsymbol{\nabla})$ of Cloisite $^{\circledR} 20 \mathrm{~A}$

ibilizer is used. In fact, for both Lupolen and Eltex based nanocomposites the creep compliance is reduced when a $2 \mathrm{wt} \%$ of clay and a $10 \mathrm{wt} \%$ of compatibilizer are added. It is wortwhile to note that if an higher amount of clay is added ( $5 \mathrm{wt} \%$ ) no further improvements of the creep resistance are observed. In particular, even if the elastic component of the creep compliance is reduced, this effect is negatively counterbalanced by an increase of the viscoelastic component.
The creep behaviour as a function of the PEgMA content has been investigated for Lupolen based nanocomposites filled with 2 and $5 \mathrm{wt} \%$ of Cloisite $^{\circledR}$ 20A. The creep compliance and its elastic and viscoelastic components are reported in Figure $5 \mathrm{a}, 5 \mathrm{~b}$ and $5 \mathrm{c}$, respectively.

For all the compatibilized samples, the introduction of clay leads to a decrease of the total compliance with respect to the corresponding unfilled matrices. At he same time, it is possible to note that when the clay amount is increased to $5 \mathrm{wt} \%$ the creep compliance increases, with the only exception of the samples with $30 \mathrm{wt} \%$ of PEgMA. This trend can be tentatively explained by considering that the elastic creep component is reduced proportionally to the clay amount as expected (see Figure 5b), while the viscoelastic component is negatively affected by the presence of an high percentage clay (see Figure $5 b$ ). The viscoelastic component of the creep compliace represents the solid-state flow behaviour of the materials, which is most probably governed by the yield strength. In fact, similarly to the yield strength, the peculiar trend of the viscoelastic component of the creep compliace could be tentatively related to a possible lubricating effect of the clay platelets at this loading level.

\section{Conclusions}

Polyethylene - clay nanocomposites were produced by melt compounding, using two HDPEs with different melt flow rate, two different organo-modified clays, and changing the relative amount of PEgMA compatibilizer.

The intercalation process is more effective as the matrix melt viscosity decreases (higher MFR), while the clay interlamellar spacing increases as the compatibilizer amount increases. Cloisite ${ }^{\circledR} 20 \mathrm{~A}$ filled nanocomposites show better intercalation and mechanical properties than Cloisite ${ }^{\circledR}$ 15A filled samples.

The relative stiffness of the nanocomposites increases with the addition of clay, with a limited enhancement of the relative yield stress. The better intercalation obtained by the addition of the compatibilizer is not accompanied by a concurrent improvement of the tensile mechanical properties. The creep resistance is enhanced by the introduction of clay that induces a decrease of the creep compliance, provided that the PEgMA compatibilizer is added. 


\section{Acknowledgements}

This research was party supported by Eurostandard SpA (Tesero - Trento, Italy). The authors express their appreciation to DuPont (Dr. Tatiana Damian, Packaging \& Industrial Polymer) for the kind provision of the PEgMA compatibilizer used in this research.

\section{References}

[1] Mandalia T., Bergaya F.: Organo-clay mineral-melted polyolefin nanocomposites. Effect of surfactant/CEC ratio. Journal of Physics and Chemistry of Solids, 67, 836-845 (2005).

[2] Zhang J., Jiang D. D., Wilkie C. A.: Thermal and flame properties of polyethylene and polypropylene nanocomposites besed on an oligomerically moified clay. Polymer degradation and stability, 91, 298-304 (2006).

[3] Yuan Q., Misra R. D. K.: Impact fracture behaviour of clay-reinforced polypropylene nanocomposites. Polymer, 47, 4421-4433 (2006).

[4] Bergaya F., Mandalia T., Amigouet P.: Abrief survey on CLAYPEN and nanocomposites based on unmodified PE and organo-pillared clays. Colloid Polymer Science, 283, 773-782 (2005).

[5] Lu H., Hu Y., Xiao J., Kong Q., Chen Z., Fan W.: The influence of irradiation on morphology evolution and flammability properties of maleated polyethylene/clay nanocomposite. Materials Letters, 59, 648-651 (2005).

[6] Osman M. A., Rupp J. E. P., Suter U. W.: Effect of non-ionic surfactants on the exfoliation and properties of polyethylene-layered silicate nanocomposites. Polymer, 46, 8202-8209 (2005).

[7] Chrissopolou K., Altintzi I., Anastasiadis S. H., Giannelis E. P., Pitsikalis M., Hadjichristidis N., Theophilou N.: Controlling the miscibility of polyethylene/layered silicate nanocomposites by altering the polymer/surface interactions. Polymer, 46, 1244012451 (2005).

[8] Su S., Jiang D. D., Wilkie C. A.: Polybutadiene modified clay and its nanocomposites. Polymer Degradation and Stability, 84, 279-288 (2003).

[9] Wang K. H., Xu M., Choi Y. S., Chung I. J.: Effect of Aspect Ratio on melt extensional process of maleated polyethylene/clay nanocomposites. Polymer Bulletin, 46, 499-505 (2001).

[10] Su S., Jiang D. D., Wilkie C. A.: Poly(methyl methacrylate), polypropylene and polyethylene nanocomposite formation by melt blending using novel polymerically modified clay. Polymer Degradation and Stability, 83, 321-331 (2004).

[11] Zhang J., Jiang D. D., Wilkie C. A.: Polyethylene and polypropylene nanocomposites based upon an oligomerically modifed clay. Thermochinica Acta, 430, 107-113 (2005).

[12] Zhao C., Qin H., Gong F., Feng M., Zhang S., Yang M.: Mechanical, thermal and flammability properties of polyethylene/clay nanocomposites. Polymer Degradation and Stability, 87, 183-189 (2005).

[13] Gopakumar T. G., Lee J. A., Kontopoulou M., Parent J. S.: Influence of clay exfoliation on the physical properties of montmorillonite/polyethylene composites. Polymer, 43, 5483-5491 (2002).

[14] Wang K. H., Choi M. H., Koo C. M., Xu M., Chung I. J., Jang M. C., Choi S. W., Song H.H.: Morphology and physical properties of polyethylene/silicate nanocomposite prepared by melt intercalation. Journal of Polymer Science: Part B: Polymer Physics, 40, 1454-1463 (2002).

[15] Wang K. H., Koo C. M., Chung I. J.: Physical properties of polyethylene/silicate nanocomposite blown films. Journal of Applied Polymer Science, 89, 2131-2136 (2002).

[16] Kato M., Okamoto H., Hasegawa N., Tsukigase A., Usuki A.: Preparation and properties of polyethyleneclay hybrids. Polymer Engineering and Science, 43, 1312-1316 (2003).

[17] Hotta S., Paul D. R.: Nanocomposites formed from linear low density polyethylene and organoclays. Polymer, 45, 7639-7654 (2004).

[18] Liang G. D., Xu J. T., Bao S. P., Xu W. B.: Polyethylene maleic anhydride grafted polyethylene organic-montmorillonite nanocomposites. I. Preparation, microstructure, and mechanical properties. Journal of Applied Polymer Science, 91, 3974-3980 (2004).

[19] Zhao C. G., Feng M., Gong F. L., Qin H. L., Yang M. S.: Preparation and characterization of polyethyleneclay nanocomposites by using chlorosilane-modified clay. Journal of Applied Polymer Science, 93, 676680 (2004).

[20] Lee J. H., Jung D., Hong C-E., Rhee K. Y., Advani S. G.: Properties of Polyethylene-layered silicate nanocomposites prepared by melt intercalatin with a PP-gMA compatibilizer. Composites Science and Technology, 65, 1996-2002 (2005).

[21] Modesti M., Besco S., Lorenzetti A., Zanirato G., Rauli F.: Reinforcing effect of organo-modified layered silicates in high-density polyethylene. Journal of Nanoscience and Nanotechnology, 5, 958-963 (2005).

[22] Morawiec J., Pawlak A., Slouf M., Galeski A., Piorkowska E., Krasnikowa N.: Preparation and properties of compatibilized LDPE/organo-modified montmorillonite nanocomposites. European Polymer Journal, 41, 1115-1122 (2005).

[23] Ranade A., Nayak K., Fairbrother D., D’Souza N. A.: Maleated and non maleated polyethylene-montmorillonite layered silicate blown films: creep, dispersion and cristallinity. Polymer, 46, 7323-7333 (2005).

[24] Tanniru M., Yuan Q., Misra R. D. K.: On significant retention of impact strength in clay-reinforced highdensity polyethylene (HDPE) nanocomposites. Polymer, 47, 2133-2146 (2006).

[25] Truss R. W., Yeow T. K.: Effect of exfoliation and dispersion on the yield behavior of melt-compounded polyethylene-montmorillonite nanocomposites. Jour- 
nal of Applied Polymer Science, 100, 3044-3049 (2006).

[26] Xie Y. C., Yu D. M., Kong J., Fan X. D., Qiao W. Q.: Study on morphology, crystallization behaviors of highly filled maleated polyethylene-layered silicate nanocomposites. Journal of Applied Polymer Science, 100, 4004-4011 (2006).

[27] Zhong Y., De Kee D.: Morphology and properties of layered silicate-polyethylene nanocomposite blown films. Polymer Engineering and Science, 45, 469-477 (2005).

[28] Shah R. K., Paul D. R.: Organoclay degradation in melt processed polyethylene nanocomposites. Polymer, 47, 4075-4084 (2006).

[29] Pegoretti A., Dorigato A., Penati A.: Production and characteization of polyurethane-clay nanocomposites. in $2^{\text {nd }}$ International Symposium on 'Nanostructured and Functional Polymer-based Materials and Nanocomposites'. 2006. Lyon, France.

[30] Fornes T. D., Yoon P. J., Hunter D. L., Keskkula H., Paul D. R.: Effect of organoclay structure on nylon 6 nanocomposite morphology and properties. Polymer, 43, 5915-5933(2002).

[31] Gianelli W., Ferrara G., Camino G., Pellegatti G., Rosenthal J., Trombini R. C.: Effect of matrix features on polypropylene layered silicate nanocomposites. Polymer, 46, 7037-7046 (2005).

[32] Shah R. K., Paul D. R.: Organoclay degradation in melt processed polyethylene nanocomposites. Polymer, 47, 4075-4084 (2006).

[33] Zhai H. B., Xu W. B., Guo H. Y., Zhou Z. F., Shen S. J., Song Q. S.: Preparation and characterization of PE and PE-g-MAH/montmorillonite nanocomposites. European Polymer Journal, 40, 2539-2545 (2004).

[34] Zhang J., Gupta R. K., Wilkie C. A.: Controlled silylation of montmorillonite and its polyethylene nanocomposites. Polymer, 47, 4537-4543 (2006).

[35] Crawford R. J.: Plastics engineering. ButterworthHeinemann, Oxford (UK) (1998).

[36] Lakes R. S.: Viscoelastic solids. CRC Press, Boca Raton (1999).

[37] Ward I. M., Hadley D. W.: An introduction to the mechanical properties of solid polymers. Wiley Chichester (1993).

[38] Siengchin S., Karger-Kocsis J.: Creep behavior of polystyrene/fluorohectorite micro- and nanocomposites. Macromolecular Rapid Communication, 27, 2090-2094 (2006). 